\title{
LA ATENCIÓN RELIGIOSA EN LAS CÁRCELES DE URUGUAY. ACONTECIMIENTO Y DESAFÍO
}

\author{
[Religious assistance in prisons in Uruguay. Reality and challenges]
}

\author{
GABRIEL GONZÁLEZ MERLANO ${ }^{1}$
}

\begin{abstract}
Resumen
Dentro de la centenaria tradición laicista del Uruguay, la cooperación entre el Estado y la religión no se ha hecho efectivo en el ámbito estatal, no obstante su existencia como principio constitucional. Esa ausencia de lo religioso, que el Estado ha favorecido, contribuye a que el derecho humano fundamental a la libertad religiosa no sea una realidad para quienes se encuentran en situaciones que les impide acceder a la atención espiritual. El presente trabajo trae una novedad excepcional, que refiere al Protocolo de la vida y atención religiosa en las cárceles, que el gobierno nacional aprobó tiempo atrás. En este ámbito se ha concretizado la cooperación entre la religión y el Estado, la igualdad de los distintos grupos religiosos en una auténtica laicidad y el respeto a la libertad religiosa. Esta singular apertura a lo religioso constituye un verdadero desafío para que la libertad religiosa pueda ser realidad también en otros ámbitos.

Palabras clave: cooperación, laicidad, religión, libertad religiosa, atención religiosa, protocolo, cárceles

Abstract

Within the centuries-old secular tradition of Uruguay, cooperation between the State and religion has not been made effective at the state level, despite its existence as a constitutional principle. This absence of religion, which the State has favored, contributes to the fact that the fundamental human right to religious freedom is not a reality for those who find themselves in situations that prevent them from accessing spiritual care. The present work brings an exceptional novelty, which refers to the Protocol for religious life and attention in prisons, which the national government approved some time ago. In this area, cooperation between religion and the State, the equality of the different religious groups in an authentic secularism and respect for religious freedom has been concretized. This singular openness to religion constitutes a real challenge so that religious freedom can be a reality in other areas as well.
\end{abstract}

Key words: cooperation, secularism, religion, religious freedom, religious care, protocol, prisons

DOI: $10.7764 / R L D R .10 .124$

\footnotetext{
${ }^{1}$ Doctor en Derecho Canónico por la Pontificia Universidad Católica Argentina, Licenciado en Derecho Canónico por la Universidad Pontificia de Salamanca. Profesor titular de la Facultad de Derecho de la Universidad Católica del Uruguay. Área de docencia e investigación: Derecho y Religión. E-mail: ggmerlano@gmail.com
} 


\section{INTRODUCCIÓN}

Es conocida la postura existente en Uruguay respecto al fenómeno religioso. Una laicidad excluyente de centenaria tradición resultado de un proceso que no se contentó con la laicización del Estado, sino que continuó con la total secularización de la sociedad, una verdadera desacralización. Así, todo el espacio público quedó permeado por la invisibilidad de lo religioso, recluido en la intimidad individual.

Esta posición, sin duda original y extraña en el concierto del derecho comparado, está basada fundamentalmente en una inveterada práctica, aunque no justificada por norma constitucional alguna. Basta leer el artículo que los constituyentes de 1917 le dedicaron a la religión, en vigencia hasta hoy (artículo 5ㅇ), ${ }^{2}$ para darnos cuenta que en la letra nada obsta para que nuestro país se encamine hacia una laicidad auténticamente positiva. Esto no solo por la proclamación de libertad religiosa y de neutralidad del Estado allí contenida, sino por la explicitación del principio de cooperación del Estado con el ámbito religioso. La del artículo 5 es una formulación jurídica que podría causar envidia a cualquier observador que desconoce la realidad uruguaya.

Sin embargo, como expresamos, algo diferente sucede en la práctica y esa cooperación o colaboración entre el Estado y el fenómeno religioso no se ha desarrollado formalmente, salvo lo concretamente establecido en el precepto constitucional, es decir, la

\footnotetext{
2"Todos los cultos religiosos son libres en el Uruguay. El Estado no sostiene religión alguna. Reconoce a la Iglesia católica el dominio de todos los templos que hayan sido total o parcialmente construidos con fondos del erario nacional, exceptuándose sólo las capillas destinadas al servicio de asilos, hospitales, cárceles u otros establecimientos públicos. Declara, asimismo, exentos de toda clase de impuestos a los templos consagrados al culto de las diversas religiones". Constitución de la República Oriental del Uruguay de 1967. Montevideo: Fundación de Cultura Económica, 2011. Cuando el constituyente habla de "impuestos", la doctrina mayoritaria siempre ha entendido que refiere a todos los tributos, incluyendo tasas y contribuciones. Las leyes interpretativas así lo han explicitado, como también la jurisprudencia de la Suprema Corte de Justicia. Desde hace un tiempo ha cambiado esta interpretación en la práctica, la que se ha vuelto más restrictiva, excluyendo de la exoneración las tasas.
} 
exoneración impositiva a los templos (contribución inmobiliaria). Aunque pueda citarse algún otro tipo de colaboración, no se verifica como una cooperación específica al ámbito religioso, si bien éste se beneficia. ${ }^{3}$ En todo caso, existe cooperación en distintas actividades sociales (niñez, ancianos, salud, etc.), pero sin involucrar lo específicamente religioso. El Estado colabora con actividades desplegadas por grupos religiosos en tanto dichas actividades representan acciones sociales, con las que se ve aliviado, puesto que su acción es sustituida por grupos que a pesar de su naturaleza religiosa son considerados como cualquier organización civil.

Al Estado le interesa colaborar con el trabajo social de los grupos religiosos siempre y cuando no se haga evidente su ideario. Una especie de esquizofrenia en la que los grupos religiosos pueden desarrollar sus acciones pero sin que sobresalga la motivación de las mismas. El Estado, solo si se ve beneficiado en su tarea, promueve las actividades sociales de las entidades religiosas, pero sin que manifiesten proselitismo alguno, pues no le interesa promover la identidad y valores que estos grupos representan. De hecho, excepto la Iglesia Católica, consecuencia de haber sido la religión del Estado, ningún grupo religioso es reconocido en cuanto tal, sino como simples asociaciones civiles sin fines de lucro.

\footnotetext{
${ }^{3}$ El artículo 69 de la Constitución establece: "Las instituciones de enseñanza privada y las culturales de la misma naturaleza estarán exoneradas de impuestos nacionales y municipales, como subvención por sus servicios". Constitución de la República Oriental del Uruguay de 1967, o. cit. Entre estas instituciones se encuentran las religiosas. La ley № 12.802, artículo 134, reconoce como institutos culturales a los efectos de la exención del artículo de la Carta a los seminarios o similares de cualquier religión, a las salas y salones de diversas actividades -incluso de clases de comercio- y a las canchas y centros de deportes y entretenimientos sostenidos por las parroquias o instituciones sin fines de lucro. Para gozar de la exención, las instituciones deben contar con personería jurídica. También, el decreto 183/008, tras la reforma tributaria del año 2007, establece que los beneficios fiscales que regula el decreto 166/008 alcanzan a las actividades de las instituciones religiosas que posean las siguientes condiciones: ser persona jurídica hábil, carecer de finalidad de lucro y poseer arraigo histórico en el país. Podemos cuestionar si con ello no se está exigiendo algo que la Constitución no exige. Como vemos, estas exoneraciones y beneficios fiscales están en función del carácter cultural (artículo 69), desconociendo la naturaleza religiosa (artículo 5) de las entidades. Fuera de estos casos, que no son exenciones o beneficios exclusivos para las confesiones religiosas, no existe otra colaboración estatal a estos grupos, salvo el caso de algunos edificios (v. gr. templos) considerados patrimonio histórico o cultural, que en tal carácter pueden recibir contribución en especie para su conservación o restauración.
} 
De este modo, se verifica una total ausencia formal del factor religioso en el espacio público, expresamente impuesta por una interpretación que no hace honor a lo consagrado en la Constitución. Sin embargo, en este ámbito de abstencionismo, negacionismo, prescindencia, o como queramos Ilamarle a esta forma cómo el Estado entiende lo religioso, surge un espacio donde se desarrolla una atención y promoción de la libertad religiosa que podemos considerar ejemplar y, por cierto, "extraño" a nuestra realidad.

Nos referimos al Protocolo de la vida y atención religiosa en las cárceles, aprobado el 23 de octubre de 2013 por resolución del Instituto Nacional de Rehabilitación, que representa un modelo de asistencia espiritual en un ámbito tan delicado y necesitado como es el de las personas privadas de libertad, y que debería replicarse a otros espacios de la sociedad. Este Protocolo reviste una gran importancia, tanto a nivel formal, de acuerdo a los motivos y fundamentos que lo inspiraron, como material. Ambos aspectos serán analizados luego de que hayamos profundizado sobre la realidad del principio de cooperación entre el Estado y las entidades religiosas en nuestro país. Al final, podremos plantear algunas conclusiones que constituyen realidades y desafíos.

\section{EL PRINCIPIO DE COOPERACIÓN}

Sabemos que el principio de cooperación es uno de los pilares del derecho religioso del Estado, que junto a la laicidad, igualdad, bilateralidad, manifiestan y explicitan el principio fundamental de la libertad religiosa. Como bien lo expresa Patiño Reyes: "El principio de cooperación implica la constitucionalización del común entendimiento, bilateral o plurilateral, predicado según las relaciones entre los poderes públicos y las 
comunidades o entidades religiosas en orden a la elaboración de su estatus jurídico especifico, así como la regulación de su contribución al bien común ciudadano". ${ }^{4}$

Sin alterar los principios que garantizan la aconfesionalidad el Estado puede colaborar con el fenómeno religioso, entendiendo la colaboración no solo como reconocimiento a la autonomía de las confesiones religiosas, sino como la actitud de "favorecer el desarrollo de los intereses religiosos de los ciudadanos", o sea, la libertad religiosa. El Estado debe velar por el bien común en el respeto a las libertades, derechos, valores e igualdad de todos ante la ley. Sin embargo, ello no excluye la cooperación o colaboración con los grupos religiosos, ya que esta, "semejante por otra parte a la que el Estado mantiene o realiza con otras actividades de interés social, se dirige no tanto a salvaguardar las instituciones religiosas cuanto a salvar los valores y principios de la comunidad social". ${ }^{5}$

En el ordenamiento jurídico uruguayo, el citado artículo 5o de la Constitución establece, junto a otros principios, el de cooperación entre el Estado y el fenómeno religioso. De este modo, a texto expreso, una vez que reconoce el dominio de los templos por parte de la Iglesia Católica ${ }^{6}$ pasa a consagrar una forma de colaboración con todas las confesiones religiosos, a través de la exención impositiva: "Declara, asimismo, exentos de toda clase de impuestos a los templos consagrados al culto de las diversas religiones". ${ }^{7}$

\footnotetext{
${ }^{4}$ PATIÑO REYES, Alberto. La cooperación entre el Estado y las Asociaciones Religiosas en México. A veinticinco años de las reformas constitucionales de 1992. En: Anuario de Derecho Eclesiástico del Estado. 2018, Vol. XXXIV, p. 307.

${ }^{5}$ AZNAR GIL, Federico. La administración de los bienes temporales de la Iglesia. 2a edición. Salamanca: Publicaciones Universidad Pontificia de Salamanca, 1993, p. 93.

"Reconoce a la Iglesia Católica el dominio de todos los templos que hayan sido, total o parcialmente, construidos con fondos del Erario Nacional, exceptuándose sólo las capillas destinadas al servicio de asilos, hospitales, cárceles u otros establecimientos públicos". Constitución de la República Oriental del Uruguay de 1967. Montevideo: Fundación de Cultura Económica, 2011.

${ }^{7}$ Constitución de la República Oriental del Uruguay de 1967. Montevideo: Fundación de Cultura Económica, 2011. El comentario del artículo 5o, así como la discusión de la Convención Nacional Constituyente está suficientemente analizada en la obra de nuestra autoría: GONZÁLEZ MERLANO, José Gabriel. Derecho y Religión en Uruguay. Evolución histórica, Vol. II. Montevideo: Universidad Católica del Uruguay, 2019.
} 
Esta disposición, como las otras del mismo artículo constitucional, a pesar de ser fruto de una transacción política, ${ }^{8}$ demuestra tolerancia sin distinción de grupos religiosos. Si bien, aparentemente, propone una medida concreta y práctica en coherencia con la libertad religiosa, con una mirada mucho más crítica se podría pensar que esto no fue más que aplicar el criterio de inmunidad impositiva a toda institución sin fines de lucro -cultural, educativa, religiosa- por conocer de antemano la naturaleza y fines de las instituciones religiosas. Es decir, el resto de las instituciones tienen la carga probatoria de demostrar la ausencia de lucro perseguido. La 'gran' concesión para los templos fue evitarles dicha prueba, por ser un hecho notorio. ${ }^{9}$

Apartándonos del fundamento de la exención, lo cierto es que el constituyente ha establecido la inmunidad impositiva para todos los templos de todas las entidades religiosas, lo que ha sido uno de los argumentos manejados por los laicistas para tratar de calificar el modo de relacionamiento entre el Estado y la Iglesia Católica como "separación benévola". Con ello se valora la contribución de la religión a la sociedad, de lo contrario no existiría tal ayuda. El Estado no invierte en aquello que se opone o no concurre con sus fines.

Es de destacar, además, que la fórmula de la Constitución de 1918 establecía la exoneración para "los templos 'actualmente' consagrados", habiéndose quitado en la reforma constitucional de 1934 el "actualmente", con lo que se consagró la exención totalmente abierta al futuro. Se establece, por tanto, claramente, un modo de cooperación

\footnotetext{
${ }^{8}$ La derrota del Partido Colorado, en las elecciones para elegir los miembros de la Convención Nacional Constituyente, provocó que se llegara a un pacto o transacción entre los dos principales partidos políticos. Se acordó que el Partido Colorado, especialmente su sector batllista, renunciaba a sus pretensiones jacobinas y de expropiación de los bienes eclesiásticos a cambio de que el Partido Nacional, que protegía dichos bienes, votara otro tipo de reformas que propiciaba el gobernante Partido Colorado. Nuevamente recomendamos: GONZÁLEZ MERLANO, J. G., o. cit.

${ }^{9}$ ASIAÍN, Carmen. Algunas reflexiones sobre la libertad religiosa en el Uruguay. En: Anuario Argentino de Derecho Canónico. 2003, Vol. X, pp. 27-28.
} 
económica indirecta, lo cual no es contradictorio con el sistema de separación que mantiene el Estado con la religión inaugurado hace más de un siglo. Dicho de otro modo, la valoración existente del aporte específico de las entidades religiosas a la sociedad y, por tanto, la concesión de un tratamiento fiscal diferenciado a estas asociaciones sin fines de lucro, basado en la exención, no es impropia en un Estado neutral en materia religiosa.

Ahora bien, debemos considerar que en general entre los estados y los grupos religiosos, además del modo de cooperación de tipo económico, existe otra forma de cooperación, que es la de la asistencia religiosa. Esta se define como "la posibilidad de recibir los servicios espirituales de la propia religión, a petición del interesado, en condiciones denominadas por la doctrina de 'especial sujeción' y que exigen una cierta cooperación externa por parte del Estado para concretar esa prestación”. ${ }^{10}$

Sin embargo, este tipo de colaboración entre el Estado y las entidades religiosas, a diferencia de la económica indirecta, en Uruguay no está garantizada en la práctica, es más, está excluida. Desde la separación, de la mano de la concepción estatal prescindente, al estilo de un integrismo laicista, se ha intensificado una tentación bastante común que consiste en aceptar a la Iglesia no por su especificidad, sino por lo beneficios especialmente sociales -obras asistenciales, educativas, sanitarias, etc.- que realiza. Ello es engañoso, pues, como antes señalamos, se le concede a los grupos religiosos un lugar en el ámbito público por su trabajo social, que ahorra energías al Estado, pero desconociendo su misión espiritual.

Si en alguna ocasión se considera relevante el aspecto estrictamente religioso es respecto a algunos fenómenos de religiosidad popular, que pueden llegar a ser apoyados o visibilizados de distintos modos -declaraciones de interés ministerial, días feriados, etc.-, aunque no por su aspecto espiritual, sino por el turismo interno que genera. Se trata, en

${ }^{10}$ PATIÑO REYES, A., o. cit., p. 314. 
general, de un "uso volteriano de la religión"11, lo que expresa la instrumentalización de que es objeto especialmente la Iglesia Católica, por ser la mayoritaria y más relevante histórica y culturalmente, pero también el resto de las confesiones religiosas. Mantiene vigencia el liberalismo y cierto jacobinismo presente desde la segunda mitad del siglo XIX, aunque, por conveniencia, sin su vertiente de hostilidad explícita en el terreno político y social, como en aquel tiempo.

Fácilmente, se acepta y apoya aquello que favorece y contribuye a la acción social del Estado, pero se rechaza de plano, con una actitud irracional, mediante un automatismo que sorprende, cualquier iniciativa que suponga una promoción a la libertad religiosa en su faz positiva, más allá de la mera tolerancia. ${ }^{12}$ La verdadera neutralidad debería prevenir cualquier modo de utilizar a las entidades religiosas en aquello que coincide con los fines sociales del Estado, pero no considerar su aporte en la razón pública a nivel moral o metafísico. ${ }^{13}$ Pues, la neutralidad asegura la auténtica cooperación, sin segregar en la vida pública la participación de las crencias religiosas y sin alterar la independencia en las relaciones entre el Estado y las confesiones. El hecho social religioso no puede ser meramente aceptado por los poderes públicos o utilizado solamente en lo que conviene a sus fines, debe ser valorado.

\footnotetext{
${ }^{11}$ BARRÁN, José Pedro. La espiritualización de la riqueza. Catolicismo y economía en Uruguay: 1730-1900. Montevideo: EBO, 1998. El Capítulo 7 se titula: "El uso volteriano de la religión católica".

${ }^{12}$ De esta forma, se entiende con claridad lo que sucedía a fines de 2011, cuando el Gobierno, a través del Ministerio de Desarrollo Social, alababa y tomaba como ejemplo obras sociales de la Iglesia Católica referidas a la minoridad y, al mismo tiempo, fustigaba, sin detenerse siquiera a realizar un análisis, la propuesta de los obispos uruguayos -en el contexto de una Carta Pastoral sobre el Bicentenario- de concederle efectos civiles al matrimonio religioso.

${ }^{13}$ La neutralidad del Estado es no injerencia en la conciencia de los ciudadanos, lo cual no se opone a que se reconozca lo religioso como fenómeno de la vida social y el aporte que conlleva. La utilidad social de las confesiones religiosas debe entenderse en sentido amplio, integral. "Es decir, no solo refrerida a las concretas iniciativas asistenciales -benéficas, humanitarias, educativas...- promovidas por los entes religiosos, sino también a esa realidad menos tangible, pero no menos importante, que es el progreso ético de la sociedad impulsado por las múltiples manifestaciones de sensibilidad hacia lo trascendente, sobre todo a través de la formación de conciencias propicias al fomento y cumplimiento de deberes de solidaridad". MARTíNEZ TORRÓN, Javier. Religión, derecho y sociedad. Granada: Comares, 1999, pp. 191-192.
} 
Esta actitud negativa frente al aporte que en su misión realizan los grupos religiosos a la sociedad se traduce en el hecho de que el Estado no le asegura asistencia de tipo religioso a ciertos colectivos sometidos a condiciones especiales. Con ello no se protege ni promueve la libertad religiosa de ciertas personas y grupos, como es el caso de la ausencia de atención religiosa a las Fuerzas Armadas y la Policía. Dicha falta de interés por el elemento religioso y su acción espiritual se observa, también, en la ausencia de signos y manifestaciones religiosas en todas las dependencias estatales y en los actos oficiales.

Tampoco se contempla la existencia de signos religiosos ni atención en los hospitales estatales, quedando el ingreso de personal religioso, en el caso que sea requerido por el enfermo o su familia, sujeto a la autorización de la dirección de cada centro de salud. La carencia de capellanes en el Ejército y la Policía se verifica, igualmente, en otros ámbitos públicos, como los cementerios estatales, aunque no se prohíbe el ingreso de personal religioso, cuando es solicitado por los familiares del difunto, para realizar una oración en el momento de la sepultura. Finalmente, debemos mencionar los centros de enseñanza gestionados por el Estado, dónde está expresamente prohibido difundir contenidos religiosos, y el nombre de Dios directamente proscripto.

En este contexto tan atípico, en el que a nivel constitucional se consagra una clara colaboración económica del Estado a la religión y, por otra parte, en la práctica se excluye cualquier aporte de lo religioso en su especificidad, nos encontramos, como antes dijimos, con una novedad. Esta se refiere a la asistencia religiosa a las personas privadas de libertad. Hablamos de novedad porque constituye una iniciativa que se distancia de lo que es la actitud y praxis común del Estado uruguayo en estos temas, como también es novedoso el momento político en el cual se prohijó y concretó el proyecto.

Si bien la postura prescindente ante lo religioso atraviesa transversalmente todo el sistema político, es llamativo que esta idea y su desarrollo surja de cierta fuerza política, llamada progresista, y más llamativo aún que cuente con la aprobación del resto del 
sistema político, sin que nadie haya alzado su voz invocando el vernáculo concepto de laicidad. Pero bienvenidas sean estas sorpresas si contribuyen al ejercicio de la libertad religiosa de personas sometidas a realidades que merecen una atención religiosa especial, como aquellas que se encuentran en los centros de reclusión.

Este servicio religioso a los privados de libertad contribuye, además, a dejar en evidencia lo que falta en otros sectores y grupos de la sociedad para efectivizar la libertad de religión y creencias. La contradicción que se manifiesta es elocuente por sí misma, pues a partir de este Protocolo de la vida y atención religiosa en las cárceles se libera la religión en ese ámbito penitenciario, mientras que en las escuelas, por poner un ejemplo, el solo nombre de Dios o cualquier contenido religioso es anatematizado. En el fondo, a la niñez y juventud se las "protege" de la religión, la que no se considera formativa, por lo que a las nuevas generaciones se las sigue adoctrinando en el más rancio laicismo. Sin embargo, se valora la religión como instrumento de regeneración para las personas en situación de reclusión.

También es contradictorio lo sucedido poco tiempo después de comenzar a utilizarse el Protocolo en las cárceles, cuando se citó al Parlamento al ministro de Defensa para que explicara el "atentado a la laicidad" provocado por el Comandante en Jefe del Ejército al asistir a una misa en el día del Ejército e invitar a los subalternos a la misma. Así como por el hecho de la creación de un Departamento de Asuntos Religiosos en el Hospital Militar y que al frente del mismo se hubiera puesto a un sacerdote católico, nombrado como capellán por el Arzobispado de Montevideo. Con lo cual se interpretaba que el Estado estaba asumiendo como propia una designación de la jurisdicción eclesiástica, al aceptar tal nombramiento y destinar al sacerdote para coordinar la atención religiosa en ese ámbito de sanidad militar. ${ }^{14}$

\footnotetext{
${ }^{14}$ Esta Resolución de la Dirección Nacional de Sanidad Militar, de 22 de diciembre de 2014, aunque mucho más limitada que la referente a las cárceles, ya que se refiere solo al ámbito del hospital de las Fuerzas Armadas, no tuvo un buen recibimiento y ameritó el reclamo a nivel parlamentario al que hicimos referencia. En consecuencia, dicha resolución no llegó a concretarse formalmente en la esfera del Ministerio de Defensa y el sacerdote quedó solamente con el nombramiento del arzobispo de Montevideo, como capellán de la
} 
Por eso consideramos que son motivo de celebración las iniciativas positivas que pueden ser inspiradoras para que la libertad religiosa se vaya abriendo camino en otros espacios, y que la promocionada equidad, inclusión y pluralismo alcance también el plano religioso. Sin duda, con el Protocolo de la vida y atención religiosa en las cárceles contamos con un modelo de auténtica laicidad y neutralidad estatal, que vale la pena analizar, como lo haremos seguidamente.

\section{LOS FUNDAMENTOS DE LA ASISTENCIA RELIGIOSA EN LAS CÁRCELES}

Para analizar esta forma de cooperación entre el Estado y las entidades religiosas en el espacio carcelario estatal, creemos oportuno reparar, en primer término, en los aspectos formales de esta iniciativa, en cuanto a los fundamentos y motivaciones que la originaron y los objetivos propuestos.

En ocasión de la presentación del Protocolo de la vida y atención religiosa en las cárceles, en una jornada académica realizada en la Universidad Católica del Uruguay, los principales referentes de su elaboración y concreción brindaron las claves, tanto institucionales como jurídicas, que permiten comprender cabalmente esta iniciativa a favor de una auténtica libertad religiosa. Pues, desde el momento que el Protocolo tiene como finalidad regularizar y estandarizar la vida y atención religiosa en las cárceles, supone el reconocimiento y aplicación del derecho a la libertad de religión en dicho ámbito por parte del Estado.

capilla del hospital, no del Hospital Militar, lo que excedería a la potestad eclesiástica. Lamentablemente, en nuestro país, estas iniciativas de servicio religioso son muy escasas y cuando surgen normalmente este es el resultado. 
En cuanto a los antecedentes, el Protocolo partió de una propuesta inicial elaborada por un Grupo de Trabajo Interreligioso que surgió del Foro Interreligioso, constituido tiempo atrás.

El Grupo de Trabajo, incluyó en sus diferentes instancias a las siguientes expresiones religiosas y espirituales (por orden alfabético): Afroumbandismo-Atabaque, Ba'hai, Brahma Kumaris, CREU (Consejo de Representatividad Evangélica del Uruguay), FIEU (Federación de Iglesias Evangélicas del Uruguay), Iglesia Anglicana del Uruguay, Iglesia Católica Apostólica Romana del Uruguay, Iglesia de Jesucristo de los Santos de los últimos días (Mormones), Iglesia Evangélica Luterana Unida, Iglesia Valdense, Nueva Congregación Israelita, y Testigos de Jehová. ${ }^{15}$

En la redacción, junto a los grupos religiosos, también participó la Fundación Entre Todos, que dio un aporte logístico en el proceso de elaboración, así como las autoridades del Instituto Nacional de Rehabilitación. ${ }^{16}$ Por su parte, la Universidad Católica del Uruguay, desde el Programa de Seguimiento y Estudios Penitenciarios, aportó desde lo académico, pues contaba con trabajos de investigación previos sobre las distintas prácticas religiosas dentro de las cárceles.

Javier Galdona, sacerdote católico, actor destacado en la concepción y elaboración de este Protocolo, en la apertura de la actividad académica, expresa claramente la realidad y lo que simbólicamente el mismo representa: "Lo que hemos podido hacer y vivir ha sido muy enriquecedor, como experiencia de construcción colectiva en una realidad plural, lo cual es muy destacable, porque si hay algo que sociológicamente se presenta como

\footnotetext{
${ }^{15}$ GALDONA, Javier (Coord.). Presentación y análisis del Protocolo que ubica la vida religiosa por parte de las personas privadas de libertad en la estructura penitenciaria. Montevideo: Fundación Entre Todos, 2014, p. 3. ${ }^{16}$ El Instituto Nacional de Rehabilitación, que se encuentra en la órbita del Ministerio del Interior, fue creado por el artículo 221 de la Ley de Presupuesto Nacional del Período 2010-2014.
} 
irreductible es lo religioso". ${ }^{17}$ Destaca, además "del aspecto efectivo que tiene el Protocolo, el aspecto simbólico que va mucho más allá de lo religioso, que va mucho más allá de lo penitenciario, y que también apunta a una forma de ser sociedad, de construir sociedad, de construirnos como país". ${ }^{18}$

Agrega, luego, una importante distinción: "Hay una diferencia muy grande entre el reconocimiento formal de un derecho, como en este caso es el derecho a la vida religiosa, de la implementación de los mecanismos que lo hagan efectivamente viable en un lugar muy particular de la sociedad, como lo es una unidad penitencial, un centro de detención" ${ }^{19}$ Enfatiza en la importancia del apoyo religioso dentro del acompañamiento que la sociedad pueda dar a las personas privadas de libertad, pues para quien es religioso este es "un elemento único, específico, en la construcción de la identidad, del sentido de la vida, de la posibilidad de proyectarse más allá de la circunstancia de carencia de libertad" ${ }^{20}$

Se congratula de que el Protocolo, ya en su inicio,

no sea simplemente una normativa impresa en un papel, sino que ya hoy se está implementando y es vida real; vida, porque la institucionalidad lo ha hecho vida y lo está aplicando; vida, porque los grupos religiosos están participando y asumiendo esa tarea, que desde hace mucho tiempo realizan, pero desde ahora, se lleva adelante en un marco mucho más claro, más transparente, un marco mucho más objetivo, de respeto por los derechos de las personas privadas de libertad y de guardias, operadores, autoridades, personal penitenciario y referentes

\footnotetext{
${ }^{17}$ GALDONA, Javier. Apertura del panel. En: GALDONA, Javier (Coord.). Presentación y análisis del Protocolo que ubica la vida religiosa por parte de las personas privadas de libertad en la estructura penitenciaria. Montevideo: Fundación Entre Todos, 2014, p. 7.

${ }^{18}$ Ibíd., p. 8.

${ }^{19}$ lbíd.

${ }^{20}$ Ibíd., p. 9.
} 
Gabriel González Merlano, La atención religiosa en las cárceles de Uruguay: acontecimiento y desafío.

comunitarios, todos los que participamos de esta realidad carcelaria. $^{21}$

En este sentido, para el sociólogo Gustavo Belarra, entonces jerarca del Instituto Nacional de Rehabilitación, desde el punto de vista institucional el Protocolo marca "un punto de inflexión", por lo que implica protocolizar y normalizar la participación de las diferentes expresiones religiosa en las cárceles. De alguna manera ya se hacía, pero ahora, tanto para el Instituto Nacional de Rehabilitación, como para toda la institucionalidad,

además de dar un marco general, permitió declarar una voluntad de respeto al derecho de la libre elección de la fe de toda la población privada de libertad y dar un encuadre en términos de protocolización, de estandarización de instrumentos; y por sobre todo se define algo sustantivo, proyectar una oficina de asuntos religiosos como lo declara el Protocolo en la órbita de cada Unidad. Esa fue una decisión no menor para nosotros tomar. ${ }^{22}$

Era necesario coordinar, estandarizar, "tener una oficina, un área específicamente proyectada para el intercambio con todas aquellas instituciones que se acercan a transmitir, a expresar, a compartir su fe, de manera de poder alinear toda la intervención institucional bajo un mismo concepto general". ${ }^{23}$ Sin duda que estamos antes decisiones verdaderamente trascendentes, si consideramos que es impensable que en Uruguay pueda existir en el ámbito estatal una oficina que se ocupe de asuntos religiosos.

Sin duda alguna no era una decisión fácil, ya que, como bien lo expresa Belarra, "en general nos caracteriza como uruguayos y sobre todo como Estado, decir: 'y bueno, es un

\footnotetext{
${ }^{21}$ Ibíd.

${ }^{22}$ BELARRA, Gustavo. Perspectiva institucional. En: GALDONA, Javier (Coord.). Presentación y análisis del Protocolo que ubica la vida religiosa por parte de las personas privadas de libertad en la estructura penitenciaria. Montevideo: Fundación Entre Todos, 2014, p. 14.

${ }^{23}$ Ibíd.
} 
tema de laicidad', vamos a no meternos de ninguna forma". ${ }^{24}$ Pero había que dar una institucionalización a la religión, "y los Protocolos nos garantizan eso. La estandarización de instrumentos lo que nos garantiza es dar mensajes claros a nuestros funcionarios, dar consignas, dar certezas y por sobre todo estandarizar esa intervención". ${ }^{25}$

La religión debe estar presente "desde el paradigma de inclusión, de un paradigma de segunda oportunidad" que se pretende con las personas privadas de libertad, y es responsabilidad del Instituto Nacional de Rehabilitación -del Estado- posibilitar a la población penitenciaria el ejercicio de los derechos propios de su contexto y prepararlos para la vida en libertad. Alude a que frente a la posmodernidad o modernidad líquida, con su mirada escéptica, hay que tener presente la "posibilidad de proyectar un proyecto de vida sostenible", especialmente para tantos jóvenes privados de libertad que carecen del mismo. Allí la religión puede dar un importante aporte. ${ }^{26}$

Pasando de la perspectiva institucional a la jurídica es de destacar el análisis que realizan dos juristas, quienes por sus cargos públicos en el gobierno estuvieron muy ligados a la elaboración e implementación del Protocolo. Ellos nos brindan los fundamentos jurídicos del mismo en el contexto del ordenamiento uruguayo, así como en relación al derecho internacional de los derechos humanos.

Al respecto Álvaro Garcé, entonces Comisionado Parlamentario para el Sistema Penitenciario, resalta que una "resolución administrativa, como la que aprobó este Protocolo, puede llegar a tener trascendencia histórica". Agrega que los derechos pueden reglamentarse de dos formas:

Puede darse una reglamentación que tienda a la restricción; en esa situación nos vestimos de liberales, con el traje del siglo XVIII y entonces la mejor reglamentación es la que no existe. En

\footnotetext{
${ }^{24}$ Ibíd., p. 15.

${ }^{25}$ Ibíd., p. 16.

${ }^{26}$ Ibíd., pp. 16-17.
} 
Gabriel González Merlano, La atención religiosa en las cárceles de Uruguay: acontecimiento y desafío.

cambio cuando, como en este caso, se promueve una reglamentación sana y con un buen propósito, que tiende a la afirmación de los derechos, por supuesto que estamos de acuerdo con ella. ${ }^{27}$

Afirma, además, que el Protocolo está a favor de la vida, porque está a favor de la esperanza, y "cuando se pierde la esperanza se pierde todo. El trabajo religioso, independientemente de cuál sea, permite a la persona reconstruir un proyecto de vida, si lo tenía, volver a creer en sí mismo, o tal vez generar un proyecto que quizás no tuviera". 28

Advierte que más importante que proclamar derechos es proclamar los propios deberes, allí es cuándo "el ser humano llega a lo mejor de su esencia". Por eso ve en el Protocolo "un buen equilibrio entre deberes y derechos, entre lo que se reconoce y lo que se impone como una obligación jurídicamente establecida. Hay un buen balance en ese importante aspecto, lo que es un acierto". ${ }^{29}$ Esto en el entendido que la privación de libertad suspende o afecta temporalmente derechos, como la libertad ambulatoria o la ciudadanía -artículo 80 de la Constitución-, "pero la libertad de conciencia y la libertad de expresión del pensamiento seguro que no se anulan. Sí se afecta la libertad de reunión, desde luego, por cuestiones que tienen que ver con la seguridad". ${ }^{30}$

Tampoco altera "la libertad religiosa, todo lo que tiene que ver con el derecho a esa dimensión de la vida del ser humano, no queda suspendida ni afectada. Este derecho a la vida religiosa se encuentra expresa, implícita y genéricamente establecido en la Constitución Nacional". En este sentido, repara en el artículo 5으, pero también en el artículo 26, que establece la prohibición de la pena de muerte y la cárcel como lugar de

\footnotetext{
${ }^{27}$ GARCÉ, Álvaro. Perspectiva histórico-jurídica. En: GALDONA, Javier (Coord.). Presentación y análisis del Protocolo que ubica la vida religiosa por parte de las personas privadas de libertad en la estructura penitenciaria. Montevideo: Fundación Entre Todos, 2014, p. 19.

${ }^{28}$ |bíd., p.20.

${ }^{29}$ lbíd.

${ }^{30}$ Ibíd., p. 21.
} 
rehabilitación, "lo que incluye el respeto de esta dimensión religiosa". Así como el artículo 36, que reconoce la libertad de religión, al consagrar el derecho de todo habitante a dedicarse al trabajo y a toda actividad lícita, dónde implícitamente está la actividad religiosa. Sin olvidar, por cierto, el artículo 72, que consagra los derechos inherentes a la personalidad humana, la religión entre ellos, y el artículo 332, que garantiza los derechos y, por tanto, el derecho a la vida religiosa. ${ }^{31}$

Por tanto, como advierte Garcé, a pesar que la naturaleza jurídica del Protocolo es la de una resolución administrativa, no lo rebaja, pues el Protocolo

no hizo nacer el derecho a la libertad y a la vida religiosa en las cárceles, sino que reglamentó y precisó este derecho, con la intención de asegurar su mejor efectividad y ejercicio. Esto implica un cambio en la mirada del Estado; un cambio que no viola el principio de la laicidad, para nada. Pero hay una diferencia muy clara entre sólo permitir la actividad religiosa y resolución del Estado mediante- reconocerla y reglamentarla, lo que es mucho más que la simple autorización. ${ }^{32}$

La importancia de este logro solo la entendemos a la luz de la historia de la relación entre Estado y religión en nuestro país, que es en definitiva la historia de la libertad religiosa. En este contexto de desencuentros y hostilidades -entre los que el autor recuerda y enumera los principales hitos-, propio del proceso de secularización del Uruguay, que desembocan en la separación entre Iglesia y Estado en la Constitución de 1917, "el Protocolo adquiere una trascendencia mucho mayor". ${ }^{33}$ Por ende, hay una

\footnotetext{
${ }^{31}$ Ibíd.

${ }^{32}$ Ibíd. p. 22.

${ }^{33}$ Ibíd. Al respecto, el autor, para ilustrar sus palabras, señala una anécdota y una reflexión, pues un amigo extranjero le comentó: "'En Uruguay tienen un calendario jacobino que no lo he visto ni siquiera en Cuba, ni allí le llaman a la Navidad fiesta de la familia. No he visto nada similar en todo el mundo'. Este contexto histórico resalta la importancia que tiene la adopción por el Estado del Protocolo sobre la vida y actividad religiosa en las cárceles". Ibíd., p. 23.
} 
diferencia respecto a lo que sucedía hace un siglo, ya que aquel era un momento de enfrentamientos y conflicto con lo religioso, en cambio hoy la mirada es diferente. "El Estado hoy aparece abierto a la construcción de espacios religiosos en las cárceles. Esos espacios se vienen gestando con tolerancia y desde la complementariedad. Este Protocolo es el resultado del trabajo conjunto de doce instituciones, a las que el Estado les ha reconocido la iniciativa" ${ }^{34}$

El Protocolo, desde lo religioso, contribuye a la reforma penitenciaria y a promover derechos. La cárcel ya no es un espacio "sin ley", o sea, un lugar de privación de derechos, de "matriz autoritaria", como en el pasado, con el consabido daño que produjo. Hoy es diferente, y

porque el Protocolo va en dirección de la vida, porque suma a la tolerancia, al encuentro y a la confianza recíproca que nos debemos como integrantes de una colectividad, cuando se firmó la resolución aprobándolo se dio un saludable paso histórico sin violar para nada la neutralidad del Estado en materia religiosa. Así seguramente será valorado en el tiempo este Protocolo. ${ }^{35}$

Por su parte, Javier Miranda, desde su posición al frente de la Secretaría de Derechos Humanos de la Presidencia de la República, aborda la importancia del Protocolo en clave de derechos humanos. Reconoce el papel que han desarrollado los derechos relacionados con la religión en la construcción de la cultura de los derechos humanos, ya que

es el primer derecho fundamental que se afianza. Motivó la inauguración de un país que hoy es primera potencia en el mundo. Antes que la libertad, que el derecho a la vida, que el

\footnotetext{
${ }^{34}$ Ibíd., pp. 26-27

${ }^{35}$ Ibíd., p. 27
} 
derecho a la integridad física, antes que eso se afirmó los derechos religiosos, la libertad de conciencia o la libertad de culto".

El derecho de religión es "el primerísimo derecho de primera generación". ${ }^{36}$ En tanto, advierte que cuando hablamos de libertad religiosa hablamos de libertad, es decir, una especie dentro del conjunto de derechos fundamentales. Es muy importante, entonces, el marco conceptual desde el que nos acercamos, porque desde una concepción liberal estamos acostumbrados "a hablar de los derechos de libertad 'frente a'" (v. gr. a la integridad física, a no dañar, a la vida), derechos que limitan el poder del Estado. Pero junto a estos derechos "están los derechos de libertad 'de"' (v. gr. expresión del pensamiento, asociación, reunión), que implican un correlativo deber, pues entre derechos y deberes existe una "implicación lógica necesaria". Frente a las libertades "frente a", que "implican una obligación de no hacer de otros, en particular del Estado", las libertades "de" "ya no implican sólo obligaciones del no hacer del otro", en algunos casos suponen prestaciones del obligado. ${ }^{37}$

En este marco teórico, la libertad religiosa tiene las dos caras:

por un lado las libertades 'frente a' que está asociada a la libertad de conciencia -usted no puede imponerme a mí creer o no creer, usted no puede imponerme a mí creer en un dios o en otro- que implican definitiva libertad de elegir -insisto- elegir en conciencia libremente qué opción tomo, ya sea la de creer como la de no creer y no forzarme a creer en esto o no creer en nadie. Pero también la libertad 'de' ejercer públicamente esa opción que yo adopté; y ahí viene la asociación de la libertad religiosa ya

\footnotetext{
${ }^{36}$ MIRANDA, Javier. Perspectiva desde los derechos humanos. En: GALDONA, Javier (Coord.). Presentación y análisis del Protocolo que ubica la vida religiosa por parte de las personas privadas de libertad en la estructura penitenciaria. Montevideo: Fundación Entre Todos, 2014, p. 29.

${ }^{37}$ Ibíd., p. 30.
} 
no únicamente con la libertad de conciencia sino con la libertad de opinión y de expresión de la opinión. Este es el doble cariz de la libertad religiosa que me parece importante. ${ }^{38}$

Miranda claramente concibe la libertad religiosa en un sentido muy amplio, unida a la libertad de conciencia e implicada en un haz de libertades fundamentales. En concreto, "la opción religiosa y la opción por la expresión de la opción religiosa constituyen aspectos de autodefinición y autorreconocimiento del titular de ese derecho". La opción religiosa, aun el ateísmo o el agnosticismo, define en buena medida lo que somos como personas, nos identifica, y no solo individualmente,

sino en la construcción social del sujeto, eso define también buena parte de mis pertenencias a colectivos y aquí aparece también como manifestación de derechos colectivos y de identidades colectivas. Y aquí se asocia, entonces, no sólo con derechos individuales sino con derechos colectivos. Además y fundamentalmente con derechos culturales, derechos colectivos, con la interdependencia entre la vinculación que existe entre los derechos fundamentales. Cómo es imposible aislarlos, analizarlos cual partículas atómicas, sino que aparecen integrados y cohesionados. ${ }^{39}$

Recuerda que ello está presente en las normas internacionales de derechos humanos, como en el artículo 18 de la Declaración Universal de Derechos Humanos de 1948, también en el artículo 18 de la Convención de Derechos Civiles y Políticos, y en el artículo 27 del Pacto de San José de Costa Rica. Así como menciona, también, la Convención de Derechos del Niño, la cual, en el artículo 14, expresamente los reconoce

\footnotetext{
${ }^{38}$ Ibíd., pp. 30-31.

${ }^{39}$ Ibíd., p. 31.
} 
como titulares de derechos y, por tanto, también de los derechos de conciencia y de religión. ${ }^{40}$

Frente a este marco de derechos religiosos, opina Miranda que

el Estado laico no quiere decir un Estado que 'pasa' de las prestaciones necesarias para las realizaciones de derechos fundamentales como los derechos religiosos. Aunque parezca paradójico, lo planteo paradójico porque suena paradójico. La laicidad no es únicamente 'no me meto', 'laissez faire, laissez passer' o la mera tolerancia. El Estado laico sí es un Estado tolerante pero además es un Estado garantista; el Estado que crea las condiciones para el ejercicio pleno de todos los derechos fundamentales, incluidos los derechos de libertad religiosa, incluidos los derechos culturales implicados en las opciones religiosas de las personas. No es el que pasa. ${ }^{41}$

Un verdadero alegato de laicidad positiva, nada común en el planteo negacionista y excluyente que en el ámbito académico tiene el tema en nuestro país. Incluso, para clarificar más su postura, el autor plantea que dentro de las obligaciones que le exigimos al Estado en materia de derechos económicos, sociales y culturales está la de respetar y no dañar esos derechos, así como la de garantizar que terceros no dañen a los titulares de sus derechos, y en su caso sancionar al responsable y obligar a reparar el daño. Pero no termina aquí la función del Estado, pues se abre para éste una tercera vía de obligaciones, que es la de

realizar derechos, realizar prestaciones. Esto es absolutamente trasladable en muchísimos derechos civiles y políticos, se ve en la

\footnotetext{
${ }^{40}$ Ibíd.

${ }^{41}$ Ibíd., pp. 31-32.
} 
partición clásica del 66, en los pactos del 66, pero en particular a estos derechos que nos interesan, este derecho fundamental que son los derechos religiosos, para hablarlo en plural. El Estado debe respetar, debe tolerar, debe no hacer; pero además debe garantizar que otros no agredan esos derechos, pero además el Estado debe realizar las prestaciones necesarias para que ese derecho pueda ser ejercido. Eso no viola la laicidad del Estado, al contrario, afirma la laicidad del Estado. El Estado laico es el Estado que permite la realización también de los derechos religiosos. ${ }^{42}$

Por ello, Miranda concluye que "una persona privada de libertad no tiene limitada la libertad de conciencia ni la libertad de expresión de la opinión de su creencia. No tiene limitado ningún derecho religioso". Y alerta: "No privemos por vía de hecho la posibilidad de ejercicio de estos derechos y pongamos, en consecuencia, no sólo que el Estado respete los derechos religiosos de las personas privadas de libertad, sino que también garantice y realice prestaciones concretas para la realización de este derecho". ${ }^{43}$

Desde ahí resalta el valor "histórico" y "revolucionario" que tiene el Protocolo:

Este Protocolo que hoy nos presentan es un instrumento justamente que implica el poner a disposición mecanismos para la realización de los derechos religiosos. Establecemos procedimientos, establecemos deberes, garantías y derechos para la realización de ese derecho. Lo ponemos en práctica efectivamente, promovemos el ejercicio de un derecho fundamental en las situaciones de encierro, en las situaciones de personas privadas de libertad. Es eso. En ese marco se encuadra.

\footnotetext{
${ }^{42}$ Ibíd., p. 32.

${ }^{43}$ Ibíd., p. 33.
} 
No debería llamarnos la atención, pero es bueno que nos llame la atención que desde la institucionalidad del Estado, desde el INR se esté promoviendo este Protocolo. Es una buena cosa, una muy buena cosa. Yo coincido que es algo histórico, revolucionario. No tengo duda. ${ }^{44}$

Finalmente, destaca, como de hecho lo hacen todos, que el Protocolo es el resultado del diálogo, de la construcción común en la que participó el Estado con diversas confesiones religiosas -organizaciones de la sociedad civil-, capaces de crear consensos que hay que privilegiar. "No sólo la realización del derecho fundamental sino del proceso de construcción de los acuerdos para la realización de derechos. Éste es un ejemplo a seguir". 45

Sin duda que desde el punto de vista formal, en cuanto a sus fundamentos y motivaciones, de acuerdo a los testimonios de los participantes en la iniciativa y elaboración, el Protocolo representa un ejemplo de acción conjunta entre el Estado y las entidades religiosas, y de estas entre sí, con el fin de proteger, promover y efectivizar el ejercicio del derecho humano fundamental a la libertad religiosa. Es clara la conciencia que el derecho a la libertad de religión y creencias no solo debe ser respetado por parte del Estado, sino garantizado y promovido con acciones concretas, como es el caso de este Protocolo.

Queda de manifiesto que las convicciones religiosas de las personas, en concreto las privadas de libertad, no puede verse disminuidas por su condición de reclusión. En este sentido, se tiene en cuenta que se trata de un derecho para ser ejercido, porque las creencias no son convicciones abstractas, sino que se encarnan y concretizan en la vida cotidiana. Para este logro es necesaria la inclusión, también en el orden religioso y espiritual, manifestada en el respeto por la diversidad de creencias.

\footnotetext{
${ }^{44}$ Ibíd.

${ }^{45}$ Ibíd., pp. 33-34.
} 
Es visible la importancia que se le atribuye a la religión en orden a trasmitir valores y generar una cultura de paz. En ese aspecto, son muy elocuentes las palabras de Luis Mendoza, Director Nacional del Instituto Nacional de Rehabilitación, quien en el prólogo del Protocolo expresa:

El INR se encuentra abocado a seguir avanzado en la generación de actividades para la población que impacten directamente en la disminución del ocio compulsivo, y a su vez, las propuestas religiosas y espirituales deben estar a disposición de toda las población privada de libertad que desee asistir y participar de las mismas. En el entendido de que las propuestas religiosas y espirituales además de ser parte del derecho al libre culto impactan en la disminución de la tensión y el conflicto interpersonal, estamos confiados que el presente Protocolo fortalecerá estos espacios en todas las Unidades de Internación de Personas Privadas de Libertad redundando en una mejor gestión penitenciaria. ${ }^{46}$

\section{EL CONTENIDO DEL "PROTOCOLO DE LA VIDA Y ATENCIÓN RELIGIOSA EN LAS CÁRCELES”}

La estructura del Protocolo consta de seis partes diferenciadas, que cubren los distintos aspectos de la protección de la libertad religiosa de las personas en reclusión. A tal efecto, los puntos tratados son los siguientes: el ámbito de aplicación, los derechos de

\footnotetext{
${ }^{46}$ INSTITUTO NACIONAL DE REHABILITACIÓN. Protocolo de la Vida y Atención Religiosa en las Cárceles, aprobado el 23 de octubre de 2013. Resolución 421/13 [consulta: 28 agosto 2020]. Disponible en: https://caritasuruguaya.org.uy/nuevo/wp-content/uploads/Protocolo-Atenci\%C3\%B3n-Religiosa-Aprobadopor-el-INR-oct-2013-librillo-publicado.pdf, p. 3.
} 
libertad de religión de las personas privadas de libertad, la atención religiosa y espiritual, los referentes religiosos, las actividades religiosas, y los encuentros con los referentes religiosos.

En cuanto al ámbito de aplicación o alcance, refiere a las personas privadas de libertad y su familia, personal de guardia y familia, así como otros actores civiles (maestros, médicos, asistentes sociales, etc.). Ello fundado en el hecho de que "las personas privadas de libertad mantienen en toda su vigencia el derecho a la libertad de conciencia y de religión, incluida su expresión pública y su práctica como expresión de los Derechos Humanos inalienables". Esto se concretiza en "acciones organizadas", por lo que el Protocolo regula acciones que "participan orgánicamente de Instituciones Religiosas y Espirituales formalmente constituidas", excluyendo, por tanto, las acciones individuales.

El derecho a la libertad religiosa que se pretende regular supone el manifestar la fe a través de la participación en los ritos y celebraciones propias, así como poder compartir momentos de reflexión con los Referentes Religiosos que acudan a las unidades penitenciarias. Este derecho que presentan las personas privadas de libertad respecto a la atención religiosa, supone el interés de las distintas entidades religiosas en ofrecer este servicio. Por lo tanto, el Protocolo ordena las iniciativas institucionales en tal dirección, sometiendo las mismas a ciertos requisitos que deben ser cumplidos:

Todas aquellas Instituciones que mantengan interés en ofrecer atención religiosa y espiritual en el ámbito de las Unidades Penitenciarias, deberán presentar ante el Instituto Nacional de Rehabilitación la documentación correspondiente, a fin de acreditar la personería jurídica invocada, la que deberá estar acompañada por una descripción de las actividades que se pretenden realizar en el interior de las instalaciones penitenciarias. Se establecerá las Unidades Penitenciarias a ser atendidas y a su vez una lista de las 
personas (Referentes Religiosos) que realizarán las actividades propuestas. La totalidad de la documentación deberá estar debidamente firmada por autoridad competente de la referida Institución Religiosa o expresión espiritual. La Dirección del Instituto Nacional de Rehabilitación tomará debida cuenta de la solicitud formulada, a fin de considerar la posibilidad de aprobar o denegar la misma. En caso de que el requerimiento sea desestimado, se expondrán las razones correspondientes o en su defecto se propondrán los cambios que se entiendan oportunos realizar. ${ }^{47}$

Tal organización del servicio religioso requiere, en la medida que sea posible, la creación en cada centro de reclusión de una Oficina de Programas Religiosos, con un espacio físico y funcionarios destinados a tal fin. Este espacio, que integra las diversas manifestaciones religiosas allí presentes, tiene como cometidos: velar por el efectivo goce de la libertad de religión, organizar acciones que efectivicen ese derecho, servir de nexo entre la Unidad Penitenciaria y las Instituciones Religiosas presentes en ese establecimiento, promover con las instituciones religiosas eventos y proyectos formativos, coordinar las acciones religiosas de acuerdo al funcionamiento de la Unidad Penitenciaria, coordinar con las Instituciones Religiosas apoyo a quienes estén en situación de pre-egreso en orden a la reinserción social, llevar un registro de las Instituciones Religiosas sobre asistencia y actividades, instruir a nuevos Referentes Religiosos sobre la normativa a cumplir, identificar y designar reclusos que actúen como coordinadores de la Oficina de Programas Religiosos con lo cual podrían redimir pena. ${ }^{48}$

Por su parte, las autoridades carcelarias, salvando las normas disciplinares internas y la seguridad del establecimiento carcelario, deberán asegurar la plena manifestación de las creencias de los privados de libertad, tanto en forma personal como colectiva, así como la de las distintas expresiones religiosas con el único límite de no comprometer las

\footnotetext{
${ }^{47}$ Ibíd., pp. 10-11.

${ }^{48}$ Ibíd., pp. 11-12.
} 
condiciones de seguridad; asegurar el acceso de los Referentes Religiosos debidamente identificados, en el día y hora coordinado con la Oficina de Programas Religiosos; disponer de un espacio físico adecuado para las actividades, y asegurar el ágil diligenciamiento de las solicitudes de las personas privadas de liberad que requieran asistencia religiosa a su elección. $^{49}$

Junto al espacio de posibilidades que se abren a las distintas entidades religiosas para que desarrollen su tarea en el ámbito carcelario, se encuentran las correlativas responsabilidades, lo que supone que debe ser presentada a las autoridades del Instituto Nacional de Rehabilitación una propuesta de trabajo que señale objetivos y metodología, la nómina de personas que concurrirán en nombre de la Institución Religiosa -los Referentes Religiosos-, mantener esta lista actualizada y cuidar que cumplan su función debidamente.

En cuanto a la figura de los Referentes Religiosos, que inaugura el Protocolo, se los define como "todas aquellas personas que han sido presentadas formalmente por una Institución Religiosa registrada en el Instituto Nacional de Rehabilitación, a efectos que actúen como representantes de su expresión religiosa en una determinada Unidad Penitenciaria". Los Referentes Religiosos poseen derechos y deberes. Los derechos de que gozan son los siguientes:

a) Los Referentes Religiosos podrán ingresar a las Unidades Penitenciarias una vez que hayan sido presentados por la Institución Religiosa a la que pertenecen y hayan sido aceptados por la autoridad competente.

b) Tendrán derecho a tener un procedimiento de ingreso preferencial respecto a las visitas de familiares. En este sentido se implementará un documento de identificación emitido por la

\footnotetext{
${ }^{49}$ Ibíd., pp. 12-13.
} 
autoridad competente, el que tendrá la finalidad de acreditar su carácter de Referentes Religiosos autorizados.

c) Tendrán derecho a permanecer dentro de los recintos penitenciarios autorizados, el tiempo necesario para realizar las actividades propias de su creencia religiosa, de acuerdo a lo coordinado con la Oficina de Programas Religiosos respectiva.

d) En las Unidades Penitenciarias donde ello sea posible, podrán solicitar el acceso al sector de celdarios para atender situaciones particulares de algunas Personas Privadas de Libertad, en un ámbito de mayor intimidad y confianza con las mismas, con la autorización expresa del Director o Responsable de la Unidad Penitenciaria.

En cuanto a los deberes, tenemos los siguientes:

a) Actuar en consonancia del plan de actividades presentado oportunamente por la Institución Religiosa y/o Espiritual a la que pertenecen, informando de desvíos y nuevas situaciones que se presenten y que puedan requerir consideración por las autoridades competentes.

b) Guardar respeto y gentileza frente a las Personas Privadas de Libertad y a los funcionarios.

c) Respetar las normas de seguridad impuestas en las diferentes Unidades Penitenciarias y en los distintos momentos de la jornada. d) Permitir y colaborar en el caso de que sea requerida la revisión personal de acuerdo a los procedimientos establecidos en cada Unidad Penitenciaria.

e) Respetar los parámetros en este Protocolo..$^{50}$

\footnotetext{
${ }^{50}$ Ibíd., pp. 14-15.
} 
La actividad de atención religiosa, en la medida que debe entenderse como una práctica que requiere un tiempo determinado, que, incluso, puede llegar a una jornada, deberá tenerse en cuenta por las autoridades penitenciarias a la hora de programar las actividades diarias (trabajo, educación, salud, etc.). En cuanto al tipo de actividades religiosas, estas pueden ser permanentes, extraordinarias o educativo-formativas. Las primeras, por su carácter recurrente, deben contener objetivos, criterios metodológicos, periodicidad, días y horarios. Si en un lapso de sesenta días no hay actividad sin causa fundada, la Institución "será excluida del Registro de Instituciones Religiosas y/o Espirituales autorizadas".

Las actividades extraordinarias son aquellas no sistemáticas, como cultos, eventos, festividades, etc., a coordinar con la Oficina de Programas Religiosos. Estas actividades están abiertas a la posibilidad de ser compartidas con los familiares de los reclusos, previa autorización y evaluación correspondiente, salvaguardando siempre la seguridad de la Unidad Penitenciaria. Finalmente, las actividades educativo-formativas, una vez evaluadas como pasibles de implementar, eventualmente podrían aprobarse como proyecto de educación no formal. Esta propuesta deberá contener: la carga horaria a dictar, las materias curriculares, el currículum vitae de los docentes y los insumos de trabajo para el desarrollo de la misma. ${ }^{51}$

El último punto que trata el Protocolo se refiere a "la conveniencia de la realización de reuniones de intercambio de experiencias y propuestas para la mejora de la actuación de las distintas expresiones religiosas y/o espirituales así como con las autoridades de los Centros de reclusión". Dichas reuniones serán informales, es decir, excluyendo cualquier toma de decisiones, pues los asuntos que las requieran serán canalizados por los Referentes Religiosos con sus respectivas autoridades. Habrá dos tipos de reuniones: la de los Referentes Religiosos de las distintas expresiones religiosas entre sí y la de estos con las autoridades penitenciales.

\footnotetext{
${ }^{51}$ Ibíd., pp. 15-16.
} 
En ambos casos la periodicidad de las reuniones, a cargo de cada Oficina de Programas Religiosos, será al menos de dos al año. En cuanto a la finalidad de las mismas, se trata de fortalecer los vínculos personales e institucionales entre las expresiones religiosas participantes, aunar criterios para las actividades religiosas en la Unidad Penitenciaria y constituir un espacio para plantear inquietudes, propuestas y observaciones que se realicen entre las Instituciones Religiosas y la Oficina de Programas Religiosos. ${ }^{52}$

\section{ADHESIÓN AL DERECHO INTERNACIONAL DE LOS DERECHOS HUMANOS}

El Protocolo se cierra con un anexo documental en el que se muestran los Convenios Internacionales en relación a la vida religiosa en las cárceles, que han sido suscritos por Uruguay. De este modo, se hace referencia a tres instrumentos, dos de los cuales son muy conocidos en cuanto a lo que consagran sobre libertad de religión y creencia: Declaración Universal de los Derechos Humanos (arts. 2 y 18) y Pacto Internacional de Derechos Civiles y Políticos (arts. 18, 26 y 27). El restante es más específico, pues alude a este derecho humano fundamental en el ámbito concreto de las cárceles. Se refiere a las Reglas mínimas para el tratamiento de los reclusos (arts. 6, 41 y 42), las que establecen:

Reglas de aplicación general. Principio fundamental. 6. 1) Las reglas que siguen deben ser aplicadas imparcialmente. No se debe hacer diferencias de trato fundadas en prejuicios, principalmente de raza, color, sexo, lengua, religión, opinión política o cualquier otra opinión, de origen nacional o social, fortuna, nacimiento u otra

\footnotetext{
${ }^{52}$ Ibíd., pp. 17-18.
} 
situación cualquiera. 2) Por el contrario, importa respetar las creencias religiosas y los preceptos morales del grupo al que pertenezca el recluso.

Religión. 41. 1) Si el establecimiento contiene un número suficiente de reclusos que pertenezcan a una misma religión, se nombrará o admitirá un representante autorizado de ese culto. Cuando el número de reclusos lo justifique, y las circunstancias lo permitan, dicho representante deberá prestar servicio con carácter continuo. 2) El representante autorizado nombrado o admitido conforme al párrafo 1 deberá ser autorizado para organizar periódicamente servicios religiosos y efectuar, cada vez que corresponda, visitas pastorales particulares a los reclusos de su religión. 3) Nunca se negará a un recluso el derecho de comunicarse con el representante autorizado de una religión. Y, a la inversa, cuando un recluso se oponga a ser visitado por el representante de una religión, se deberá respetar en absoluto su actitud.

42. Dentro de lo posible, se autorizará a todo recluso a cumplir los preceptos de su religión, permitiéndosele participar en los servicios organizados en el establecimiento y tener en su poder libros piadosos y de instrucción religiosa de su confesión. ${ }^{53}$

Agrega, finalmente, otras referencias acerca de los Derechos de las Personas Privadas de Libertad en relación a la vida religiosa. Específicamente se hace mención a las Reglas penitenciarias europeas. En dichas Reglas penitenciarias se manifiesta:

Las Personas Privadas de Libertad deben ser tratadas en el respeto de los derechos de la persona humana.

\footnotetext{
${ }^{53}$ Ibíd., pp. 20-21. Estas Reglas fueron adoptadas por el Primer Congreso de las Naciones Unidas sobre Prevención del Delito y Tratamiento del Delincuente, celebrado en Ginebra en 1955, y aprobadas por el Consejo Económico y Social en sus resoluciones 663C (XXIV) de 31 de julio de 1957 y 2076 (LXII) de 13 de mayo de 1977.
} 
Las personas privadas de libertad conservan todos los derechos, salvo aquellos que les hayan sido retirados de acuerdo con la ley por su condición de condenados a una pena de prisión o sometidos a prisión provisional.

La carencia de recursos no podrá justificar que las condiciones de detención violen los derechos de la persona.

La vida en la prisión debe garantizar la integralidad de los derechos inherentes a las personas y asegurar el acceso a oportunidades y servicios de los cuales las personas gozan en la vida en el exterior.

La privación de libertad no puede menoscabar el goce de los derechos económicos, sociales y culturales, así como tampoco los civiles. Quedan suspendidos, legalmente y en forma transitoria, únicamente el derecho a la libre circulación y al voto.

La cooperación con los servicios sociales externos y, en tanto que sea posible, la participación de la sociedad civil en la vida penitenciaria debe de garantizarse.

El derecho a la libertad de pensar, de conciencia y de religión de las personas privadas de libertad debe ser respetado.

El régimen carcelario debe estar organizado, tanto como sea posible, de manera que permita a las personas privadas de libertad practicar su religión y seguir su filosofía, participar en los servicios o en las reuniones organizadas por los representantes/referentes de dichas religiones o filosofías. Podrán asimismo recibir en privado visitas de los representantes/referentes de su religión o su filosofía y de tener en su poder libros o publicaciones de carácter religioso o espiritual.

Las personas privadas de libertad no pueden ser obligadas a practicar una religión o a seguir una filosofía, ni a participar en los servicios o reuniones religiosas o a participar en prácticas religiosas 
o a aceptar la visita de un representante/referente de una religión o de una filosofía, sean estas cuales sean. ${ }^{54}$

A la vista de lo estipulado en estos documentos sobre el derecho internacional de los derechos humanos relativo a la libertad religiosa, queda de manifiesto la libertad de creer que tienen los privados de libertad, y en ese caso el deber de facilitarles los servicios que requieran. Correlativamente, les asiste el derecho de no creer y, en tanto, no ser obligados a ir contra sus convicciones. De este modo, vemos como el Protocolo de la vida y atención religiosa en las cárceles de Uruguay está armonizado con la normativa internacional, por lo que podemos afirmar que en este aspecto nuestro país se ajusta en la práctica a lo que ha suscrito a nivel jurídico.

\section{CONCLUSIONES}

De la valoración del Protocolo de la vida y atención religiosa en las cárceles vigente en Uruguay, en el contexto de lo que supone en la práctica el principio de cooperación entre el Estado y los grupos religiosos, extraemos las conclusiones que siguen:

1. Nuestra realidad uruguaya, excluyente del factor religioso en el ámbito estatal y en el ámbito público en general, no es proclive a efectivizar el principio de cooperación entre el Estado y la religión en forma específica. Nada existe más allá de la concreta cooperación económica indirecta consagrada hace un siglo en el artículo 5으 de la Constitución. Esta postura no ayuda al desarrollo de los intereses y valores religiosos de la ciudadanía, los cuales de por sí no atentan contra los principios propios de la aconfesionalidad estatal.

\footnotetext{
${ }^{54}$ Ibíd., pp. 21-22. Estas Reglas surgen de la Recomendación REC (2006)2 del Comité de Ministros de los Estados Miembros sobre las Reglas Penitenciarias Europeas (1), adoptado por el Comité de Ministros el 11 de enero de 2006 en la 952a Reunión de Delegados de Ministros.
} 
2. Existe en Uruguay una consideración positiva hacia lo religioso solo en cuanto a su acción social. No se tiene en cuenta el ámbito religioso por su aporte específico, sino que se valora a los grupos religiosos por su tarea subsidiaria de naturaleza material, con el que el Estado ahorra energías en el plano de la asistencia social, del mismo modo que lo hace cualquier otra organización de la sociedad civil.

3. No existen modos de colaboración en el que las entidades religiosas contribuyan con su servicio espiritual a determinados colectivos (militares, policía, hospitales, etc.), que por su condición pudieran reivindicar dicho servicio. Por lo que en muchos ámbitos es ilusoria la neutralidad del Estado, al no asegurar los derechos a la vida religiosa en todas sus dimensiones. La libertad de religión no consiste solo en convicciones o creencias a nivel de conciencia, en forma individual y privada, supone prácticas que abarcan toda la vida de la persona, también en forma colectiva y pública.

4. Aparece como una novedad la creación de un Protocolo que regula la vida y atención religiosa a las personas privadas de libertad, sus familiares y los que por su trabajo están vinculadas a los centros de reclusión. Lo novedoso estriba en que se reconoce como valioso el aporte de naturaleza espiritual que brindan los grupos religiosos en este ámbito, él único de la sociedad en el que el Estado promueve lo religioso en su especificidad. A pesar de la aparente debilidad jurídica, ya que el Protocolo fue adoptado por una resolución administrativa, la fortaleza está en el significado que ese hecho jurídico entraña.

5. Esta bienvenida excepción, que se da en este espacio de los centros de reclusión, deja en evidencia la carencia de la promoción de una auténtica libertad de religión y creencias en otros sectores de la sociedad. Es llamativa la contradicción entre lo que propone este Protocolo para vivir y profesar la fe, con la proscripción de toda manifestación, enseñanza y práctica religiosa en los otros ámbitos de gestión estatal. Por ejemplo, no se puede hablar de Dios en la escuela, pero se puede celebrar una misa en la cárcel. 
6. La contradicción a la que hacemos referencia denota la falta de regulación por parte del ordenamiento jurídico estatal del fenómeno religioso, a causa de un Estado prescindente y negacionista de la importancia e influencia de este factor cultural inherente a la persona. Las iniciativas, como este Protocolo de la vida y atención religiosa en las cárceles, deben servir de ejemplo y desafío para que también puedan ser realidad en el resto de la sociedad. No decimos que en vigencia de este protocolo la atención religiosa en las cárceles se haya podido realizar siempre de la mejor forma. Vivimos en un país muy secularizado, donde estas iniciativas, aun institucionalizadas, muchas veces están supeditadas a la voluntad de los jerarcas que impiden o limitan su realización. De todos modos, ahí está el instrumento que legitima el servicio religioso.

7. Por ello, aunque heterogéneo y perfectible en su aplicación, por el secularismo reinante, destacamos el valor del Protocolo por la iniciativa que lo animó, sus fundamentos institucionales y jurídicos, los objetivos que se propone y el modo de estructurar y organizar la colaboración entre el Estado y los grupos religiosos para la atención espiritual y vida religiosa en el ámbito carcelario. El Estado no coopera destinando capellanes, pero autoriza la creación de Oficinas de Programas Religiosos dotadas de funcionarios, a la vez que facilita el acceso de personal religioso a los centros de reclusión. Así, con la estandarización de acceso y servicios, y la creación de espacios físicos para las reuniones y actividades religiosas, institucionalmente coordinadas, se expresa, en la letra, un auténtico sentido de respeto y promoción a la libertad religiosa.

8. Queda mucho por hacer para que lo religioso sea considerado en su dimensión natural y plenamente humana, como elemento que contribuye al desarrollo personal y comunitario, en otras áreas: Fuerzas Armadas, hospitales, escuelas, etc. Es necesario un mayor alcance del derecho a la libertad religiosa. Mientras tanto, nos alegramos por el logro de que en las cárceles se reconozca a la religión como instrumento que contribuye a la tarea de regenerar conductas y costumbres, un 
medio que con sus valores aporta a la rehabilitación de las personas privadas de libertad.

9. A la vez que las religiones aportan en ese espacio específico lo que le es propio, es decir, la espiritualidad, colaborando en ello con el Estado, se manifiesta en sentido pleno la igualdad de todos los grupos religiosos. Queda en evidencia la auténtica neutralidad del Estado, que siendo laico puede favorecer y promover el derecho humano fundamental a la libertad religiosa. El Estado no solo reconoce y tolera este derecho en su faz negativa de no intervención, sino que lo garantiza y promueve en su faz positiva, al disponer los medios para hacerlo efectivo.

10. Por otra parte, se refuerzan los vínculos ecuménicos e interreligiosos, con lo cual el fenómeno religioso muestra más claramente los valores que lo sostienen y su aporte a la sociedad. Del mismo modo, se remarca el pluralismo religioso como ejemplo de sana y pacífica convivencia, pues al no existir un grupo más beneficiado que otro se origina un modelo de cooperación que favorece la plena realización de la libertad religiosa. Para este logro siempre es necesario el natural entendimiento que debe manifestarse entre el Estado y los grupos religiosos.

\section{REFERENCIAS BIBLIOGRÁFICAS}

- $\quad$ ASIAÍN, Carmen. Algunas reflexiones sobre la libertad religiosa en el Uruguay. En: Anuario Argentino de Derecho Canónico. 2003, Vol. X.

- $\quad$ AZNAR GIL, Federico. La administración de los bienes temporales de la Iglesia. 2aa edición. Salamanca: Publicaciones Universidad Pontificia de Salamanca, 1993.

- $\quad$ BARRÁN, José Pedro. La espiritualización de la riqueza. Catolicismo y economía en Uruguay: 1730-1900. Montevideo: EBO, 1998. 
- $\quad$ BelarRA, Gustavo. Perspectiva institucional. En: GALDONA, Javier (Coord.). Presentación y análisis del Protocolo que ubica la vida religiosa por parte de las personas privadas de libertad en la estructura penitenciaria. Montevideo: Fundación Entre Todos, 2014.

- $\quad$ Constitución de la República Oriental del Uruguay de 1967. Montevideo: Fundación de Cultura Económica, 2011.

- $\quad$ GALDONA, Javier. Apertura del panel. En: GALDONA, Javier (Coord.). Presentación y análisis del Protocolo que ubica la vida religiosa por parte de las personas privadas de libertad en la estructura penitenciaria. Montevideo: Fundación Entre Todos, 2014.

- GARCÉ, Álvaro. Perspectiva histórico-jurídica. En: GALDONA, Javier (Coord.). Presentación y análisis del Protocolo que ubica la vida religiosa por parte de las personas privadas de libertad en la estructura penitenciaria. Montevideo: Fundación Entre Todos, 2014.

- GONZÁLEZ MERLANO, José Gabriel. Derecho y Religión en Uruguay. Evolución histórica, Vol. II. Montevideo: Universidad Católica del Uruguay, 2019.

- INSTITUTO NACIONAL DE REHABILITACIÓN. Protocolo de la Vida y Atención Religiosa en las Cárceles, aprobado el 23 de octubre de 2013. Resolución 421/13 [consulta: 28 agosto 2020]. Disponible en: https://caritasuruguaya.org.uy/nuevo/wp-content/uploads/ProtocoloAtenci\%C3\%B3n-Religiosa-Aprobado-por-el-INR-oct-2013-librillo-publicado.pdf

- $\quad$ MARTÍNEZ TORRÓN, Javier. Religión, derecho y sociedad. Granada: Comares, 1999. 
- $\quad$ MIRANDA, Javier. Perspectiva desde los derechos humanos. En: GALDONA, Javier (Coord.). Presentación y análisis del Protocolo que ubica la vida religiosa por parte de las personas privadas de libertad en la estructura penitenciaria. Montevideo: Fundación Entre Todos, 2014.

- $\quad$ PATIÑO REYES, Alberto. La cooperación entre el Estado y las Asociaciones Religiosas en México. A veinticinco años de las reformas constitucionales de 1992. En: Anuario de Derecho Eclesiástico del Estado. 2018, Vol. XXXIV. 